\title{
Family Planning for People with Multiple Sclerosis in Saudi Arabia: an Expert Consensus
}

\author{
Mohammed Al Jumah (D, ${ }^{1}$ Yaser Al Malik, ${ }^{2,3}$ Nuha M. AlKhawajah, ${ }^{4,5}$ Jameelah Saeedi, ${ }^{6}$ \\ Ibtisam AlThubaiti, ${ }^{7}$ Saeed Bohlega, ${ }^{8}$ Reem F. Bunyan, ${ }^{9}$ Edward J. Cupler, ${ }^{10}$ \\ Ahmed ElBoghdady, ${ }^{11}$ Ahmed Hassan, ${ }^{10}$ Eman Nassim Ali, ${ }^{9}$ and Marinella Clerico ${ }^{12}$ \\ ${ }^{1}$ Neurology Department, King Fahad Medical City, Riyadh, Saudi Arabia \\ ${ }^{2}$ College of Medicine, King Saud Bin Abdulaziz University for Health Sciences, Riyadh, Saudi Arabia \\ ${ }^{3}$ Division of Neurology, King Abdulaziz Medical City (National Guard Health Affairs), Riyadh, Saudi Arabia \\ ${ }^{4}$ College of Medicine, King Saud University, Riyadh, Saudi Arabia \\ ${ }^{5}$ Division of Neurology, King Saud University Medical City, Riyadh, Saudi Arabia \\ ${ }^{6}$ Neurology Department, King Abdullah Bin Abdulaziz University Hospital, Riyadh, Saudi Arabia \\ ${ }^{7}$ Neurology Department, King Fahad Military Medical Complex Dhahran, Dammam Eastern Region, Saudi Arabia \\ ${ }^{8}$ Department of Neurosciences, King Faisal Specialist Hospital and Research Center, Riyadh, Saudi Arabia \\ ${ }^{9}$ Neurology Department, King Fahad Specialist Hospital Dammam, Dammam Eastern Region, Saudi Arabia \\ ${ }^{10}$ Department of Neurosciences, King Faisal Specialist Hospital and Research Center, Jeddah, Saudi Arabia \\ ${ }^{11}$ Merck KGaA, Riyadh, Saudi Arabia \\ ${ }^{12}$ Clinical and Biological Sciences Department, University of Torino, Orbassano, Italy
}

Correspondence should be addressed to Mohammed Al Jumah; jumahm@gmail.com

Received 9 October 2020; Accepted 1 February 2021; Published 15 February 2021

Academic Editor: Pasquale Calabrese

Copyright (C) 2021 Mohammed Al Jumah et al. This is an open access article distributed under the Creative Commons Attribution License, which permits unrestricted use, distribution, and reproduction in any medium, provided the original work is properly cited.

\begin{abstract}
More than half of all patients with multiple sclerosis (MS) in the Kingdom of Saudi Arabia (KSA) are women of childbearing age. Raising a family is an important life goal for women in our region of the world. However, fears and misconceptions about the clinical course of relapsing-remitting MS (RRMS) and the effects of disease-modifying drugs (DMDs) on the foetus have led many women to reduce their expectations of raising a family, sometimes even to the point of avoiding pregnancy altogether. The increase in the number of DMDs available to manage RRMS and recent studies on their effects in pregnancy have broadened management options for these women. Interferon beta now has an indication in Europe for use during pregnancy (according to clinical need) and can be used during breastfeeding. Glatiramer acetate is a further possible option for women with lower levels of RRMS disease activity who are, or about to become, pregnant; natalizumab may be used up to 30 weeks in patients with higher levels of disease activity. Where possible, physicians need to support and encourage women to pursue their dream of a fulfilling family life, supported where necessary by active interventions for RRMS that are increasingly evidence based.
\end{abstract}

\section{Introduction}

Relapsing-remitting multiple sclerosis (RRMS) commonly arises before middle age, at a time when families are likely to be planning to have children [1]. Recent (2020) survey data from a registry in the Kingdom of Saudi Arabia
(KSA) showed that about three of every four patients with MS were aged 40 years or less at the time of their MS diagnosis [2]. Moreover, two-thirds of Saudi MS patients in this study were females, suggesting that about half of patients with MS in KSA are women of childbearing potential [2]. In addition, the prevalence of MS has been 
rising in recent decades, suggesting an increasing burden of MS among this population [2].

RRMS per se does not appear to exert an adverse effect on the course or outcome of pregnancy [3]. But, there is evidence, including in women from the Middle East, that the presence of MS leads women to avoid pregnancy (perhaps completely), due to fears or concerns about the effect of MS on their general health, the adverse effects of MS treatments on the pregnancy or on their fertility, and possible limitations of the use of fertility treatments once MS has been diagnosed $[4,5]$. Misconceptions about MS and pregnancy were common among a sample of patients in the USA [6]. Women with MS, and their partners, have the same right to pursue family life as anyone else and should be encouraged to do so [1]. However, limitations on the use of most DMDs during pregnancy (discussed below) complicate the management of their MS at this time.

The frequency of RRMS relapses decreases during the second and third trimesters, but this risk does not disappear, on average [7]. In addition, some studies have shown that there is an increased risk of relapses in the months following delivery $[7,8]$ although this was not found in a US cohort recently [9]. Continued MS disease activity depletes the capacity of the central nervous system to recover from relapses, and there is a consensus that early and continuous medical intervention in people with MS at risk of relapses is likely to ameliorate progression of disability over the long term, in KSA [10], as elsewhere [11].

A diagnosis of RRMS therefore has the potential to disrupt normal family life for many couples, where the need to facilitate a normal family life as possible must be balanced with preserving the mother's long-term outcome. An expert consensus on the management of RRMS during pregnancy is available for the UK [12], but guidance for countries such as KSA is lacking. In this article, we, a group of physicians from KSA with expertise in the management of MS, provide consensus guidance on the management of RRMS during pregnancy, with special reference to the application of DMD-based therapy for these patients.

\section{Background: Family Planning in Saudi Arabia}

Raising a family is an important life goal for people in KSA, and women in that country (who did not have MS) indicated in a survey a desire to have up to five children in some regions [13]. DMDs that have a strict contraindication in pregnancy require the application of continuous contraception, however. Contraception is accepted by many Saudis, mostly oral contraceptives or intrauterine devices, either to prevent a pregnancy or as a way of spacing out births $[13,14]$. Survey conducted in KSA found that a majority of women were using contraception, although supported by medical advice to only a limited extent $[14,15]$. Women with higher levels of education and older women with larger existing families are more likely to use contraception $[14,16]$.

Limited access to contraception, fear of side-effects, religious concerns, and opposition from the husband were important barriers to the use of contraception for Saudi women, in a survey published in 2018 [16]. Data on the proportion of unplanned pregnancies in KSA are scarce, although frequencies of $12 \%$ [17] and 23\% [18] of all pregnancies have been reported for Saudi women. The information summarised above suggests that many, but not all, Saudi women of childbearing age with MS are prepared to use contraception, but a need to do this due to DMD treatment will often conflict with the desire for a large family.

\section{Disease-Modifying Drugs and Pregnancy}

3.1. Therapeutic Indications in Europe and in the USA. Recent years have seen a considerable expansion in the number of DMDs available for the management of RRMS. Among currently available indicated for therapeutic use in people with RRMS, alemtuzumab, cladribine tablets, fingolimod, natalizumab, and ocrelizumab are considered highefficacy DMDs, usually reserved for use in patients with a history of higher disease activity [19]. The labelling of DMDs in Europe (Summary of Product Characteristics) and US (Prescribing Information) does not provide rules for prescribing that are mandatory in KSA, but they do provide useful sources of information on the level of risk to a pregnancy associated with them. This section provides a brief overview of contraindications and cautions to the use of DMDs in these labels.

At the time of writing, only interferon beta $(\operatorname{INF} \beta)$ has a clear indication for use during pregnancy, where this is justified by clinical need, according to a recent update of its European label. Other DMDs that are not formally contraindicated in Europe for use during pregnancy are glatiramer acetate (GA), dimethyl fumarate (DMF), alemtuzumab, natalizumab, and ocrelizumab: the European labels for all of these DMDs carry a statement to the effect that they should be avoided during pregnancy and used only when their benefit clearly outweighs the risks to the pregnancy. Teriflunomide, cladribine tablets, fingolimod, and siponimod are formally contraindicated during pregnancy. Labelling from the USA is more restrictive. The absolute contraindications for fingolimod, siponimod, cladribine tablets, and teriflunomide are present, but unlike European labelling, there is no support for use of ocrelizumab, natalizumab, alemtuzumab, or DMF. INF $\beta$ can be used with caution according to risk/benefit assessment in the USA, while US regulators consider that data on glatiramer acetate are insufficient to reach a conclusion.

\subsection{Practical Considerations regarding DMD-Based Therapy for Women Who Are or Plan to Become Pregnant}

3.2.1. Continuously Administered DMDs. Consideration of a female patient's plans for starting a family is important when prescribing a DMD. In the ideal situation, the patient will start on (and respond to) a DMD, make the necessary changes to the treatment regimen when she decides to become pregnant, wait until the original DMD has been cleared from the system if necessary, promptly become pregnant, and then resume treatment. In practice, needing to stop changing, a DMD is disruptive for the patient and risks a resumption of disease activity. There is also a real risk of an 
unplanned pregnancy being exposed to a DMD before it is discovered.

Table 1 summarises instructions from European labelling on the administration of DMDs with respect to family planning. Treatment with INF $\beta$ (and possibly GA) can be continued into the pregnancy and so represent a rational choice for therapy for patients with lower disease activity who may wish to become pregnant. Ocrelizumab has a long recommended washout period (12 months) before a patient should become pregnant. The recommended washout period for fingolimod is shorter (2 months), but withdrawal of this DMD risks a rebound reactivation of MS disease activity [20,21]. Siponimod, which has a similar cellular mechanism of action to fingolimod [22], has a much shorter half-life and a washout period of only 10 days. The current European indication for this agent is secondary progressive MS with active disease, rather than RRMS, however.

If a patient is considered at risk of recurrence of disease activity after withdrawal of fingolimod or siponimod, we would recommend either bridging with INF $\beta$ until treatment can be resumed postpartum or switching to natalizumab if the patient has high MS activity requiring a high-efficacy $\mathrm{DMD}$. We also recommend continuing existing natalizumab therapy until about week 30 of the pregnancy, depending on the needs of the individual patient. Use of natalizumab later in the pregnancy can result in mild-to-moderate anaemia and thrombocytopenia in the neonate [23].

3.2.2. Immune Reconstitution Therapies. Immune reconstitution therapy (IRT) has emerged in recent years as an alternative to continuous application of DMD treatment [24]. Cladribine tablets (oral administration) and alemtuzumab (given by infusion) are the two agents currently available that are believed to act as IRTs, and which are not administered continuously. Both are considered high-efficacy DMDs [19, 25, 26].

Clinical findings with both agents demonstrate a potential for a prolonged disease-free period following the 2-year treatment course, in which evidently long after effects on lymphocytes have reversed [24-26]. A patient with higher MS disease activity requiring a high-efficacy DMD, but who does not want to take a DMD during her pregnancy, may be willing to consider a trade off, where she waits until after the IRT treatment course and its recommended washout period (4 months for alemtuzumab, 6 months for cladribine tablets) to become pregnant, in return for a good possibility of conducting her pregnancy uncomplicated by either relapses or treatment with a DMD. This waiting time would be $\sim 20$ months for cladribine tablets or $\sim 16$ months for alemtuzumab (Figure 1).

3.3. Current State of the Art on the Teratogenicity of DMDs. Research into the clinical pharmacology and safety of DMDs continues, and drug labels necessarily do not always reflect the current state of knowledge. Table 2 provides a brief overview of current evidence relating to the safety of DMDs during pregnancy [27-44]. The large number of pregnancies exposed to INF $\beta$ underpins the recent relaxation of its European label with respect to use in pregnancy. The reproductive safety of GA is also supported by a substantial evidence base, although its label has not been altered to reflect this at the time of writing. Other DMDs are not yet supported by sufficient evidence to support an indication for use in pregnancy, although most physicians will be prepared to use natalizumab in pregnancy for a patient with high disease activity who requires a more efficacious drug than $\operatorname{INF} \beta$. Data on unplanned pregnancies in patients exposed to cladribine tablets are also reassuring, although this DMD retains a formal contraindication for use in pregnancy. Further studies, especially from pregnancy registries, will continue to inform the appropriate therapeutic use of DMDs in pregnant women with RRMS.

Teriflunomide is the active metabolite of leflunomide, which is used in the management of rheumatoid arthritis. Accordingly, the section of Table 2 that deals with teriflunomide also includes data on leflunomide-exposed pregnancies, for completeness. Few data are available on the outcomes of pregnancies of women whose partners are taking DMDs for RRMS. Two studies reported no adverse pregnancy outcomes from a total of 254 pregnancies of women with partners taking teriflunomide or leflunomide [42, 45].

In general, these findings are reassuring, with most reports (other than the EMA's analysis of data on fingolimod) not suggesting the presence of marked teratogenic effects of these DMD. This information may be especially useful for counselling and advising a patient who becomes pregnant unexpectedly while taking a DMD for RRMS.

\section{Disease-Modifying Drugs and Breastfeeding}

$\operatorname{INF} \beta$ is the only DMD with an unequivocal indication for use during breastfeeding, in its European label. Excretion of injected INF $\beta$ into breast milk is minimal: one study showed that the dose of INF $\beta_{1 a}$ that an infant would receive via breast milk would equate to $0.0006 \%$ of the dose received by the mother [46]. Moreover, INF $\beta$ is not active when given orally, as shown by a randomised study involving six months of oral administration of INF $\beta$, at half the maximal weekly dose given subcutaneously for the management of RRMS [47]. There was no evidence of a systemic effect, relative to placebo. These data are consistent with an absence of clinically significant exposure of the neonate to INF $\beta$ during breastfeeding.

Natalizumab is excreted into breast milk, providing doses to the infant that may have functional effects $[48,49]$. Women taking this DMD postpartum should not breastfeed. Alemtuzumab, DMF, and GA may be used during breastfeeding subject to a risk:benefit evaluation in Europe. Cladribine tablets, fingolimod (and siponimod), natalizumab (see above), ocrelizumab, and teriflunomide have formal contraindications to use in breastfeeding in Europe. US labelling permits the use of most DMDs during breastfeeding, again according to an evaluation of benefits and risks; only cladribine tablets and teriflunomide have an outright contraindication in this setting. The rapid elimination of cladribine from the system permits breastfeeding as soon as 1 week after cessation of treatment with this agent, according to its European labelling. 
TABle 1: Practical considerations relating to the use of disease-modifying drugs before and during pregnancy, according to European labelling.

\begin{tabular}{|c|c|}
\hline DMD & Potential for use before and during pregnancy \\
\hline Alemtuzumab $^{\mathrm{a}, \mathrm{b}}$ & Maintain contraception for 4 months after the end of the second-year treatment course ${ }^{c}$. \\
\hline Cladribine tablets $^{\mathrm{a}}$ & Maintain contraception for 6 months after the end of the second-year treatment course. \\
\hline Dimethyl fumarate & No recommendation given on washout period. \\
\hline Fingolimod $^{\mathrm{a}}$ & Maintain contraception for 2 months after the last dose. Withdraw immediately if pregnancy is discovered. \\
\hline Glatiramer acetate & No recommendation given on washout period. \\
\hline Interferon beta & Can be continued into pregnancy if clinically needed. \\
\hline Natalizumab $^{\mathrm{a}}$ & No recommendation given on washout period. \\
\hline Ocrelizumab $^{\mathrm{a}}$ & Maintain contraception for 12 months after the end of the second-year treatment course. \\
\hline Siponimod ${ }^{\mathrm{a}}$ & Maintain contraception for 10 days after the last dose. Withdraw immediately if pregnancy is discovered. \\
\hline Teriflunomide & $\begin{array}{l}\text { Women should not become pregnant until plasma levels of teriflunomide are }<0.02 \mathrm{mg} / \mathrm{L} \\
\text { (average } 11 \text { days if the accelerated elimination procedure is used, } 8-24 \text { months if not). Withdraw } \\
\text { immediately if pregnancy is discovered (use accelerated elimination procedure). }\end{array}$ \\
\hline
\end{tabular}

${ }^{a}$ High-efficacy DMD (see reference [19]). ${ }^{b}$ Can be used in pregnancy if clinically justified (benefits to mother outweigh risks to the foetus). Collated from European Summaries of product Characteristics (available at http://www.medicines.org.uk/, accessed October 2020). See text for differences from US Prescribing Information.
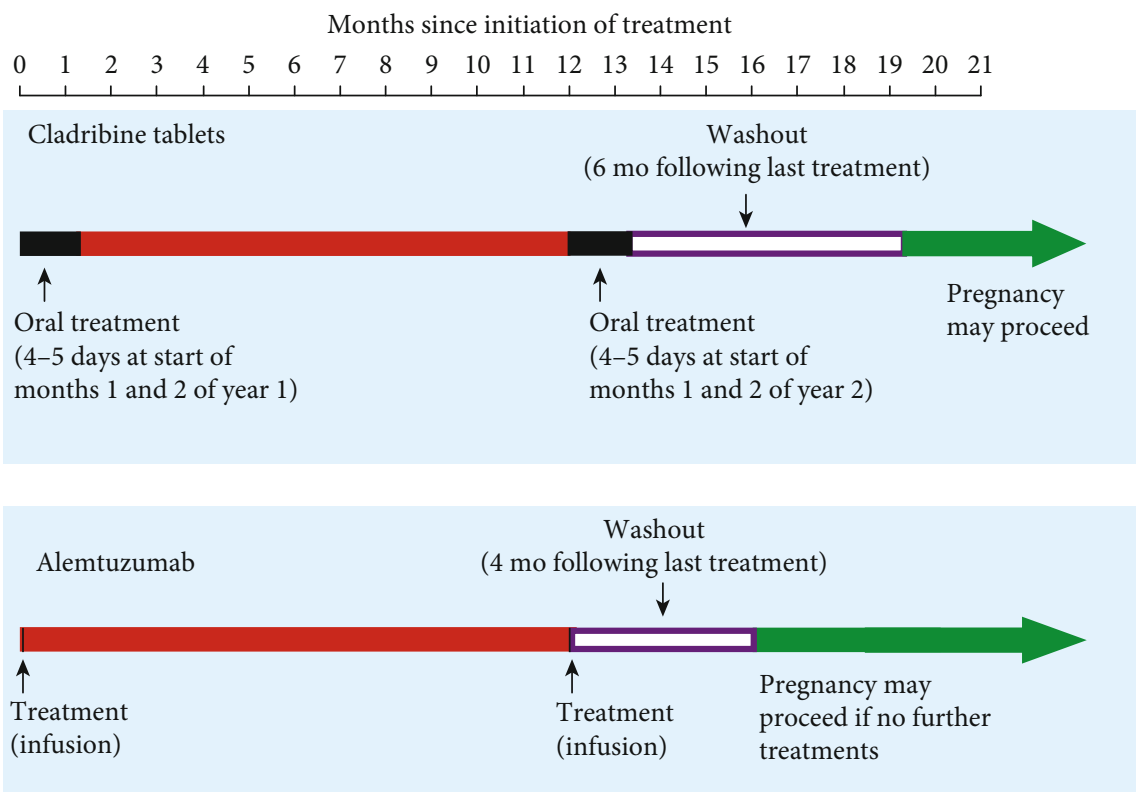

FIGURE 1: Schematic representation of the timings of treatment with disease-modifying drugs for MS that are hypothesised to act as immune reconstitution inhibitors, with regard to planning a pregnancy. Timings refer to the second year of a two-year course of treatment. If a patient becomes pregnant after only one course of treatment, the second course must be delayed until after the pregnancy (see text).

\section{Expert Opinion on Impact of Issues Related to Family Planning on Prescribing a DMD for a Woman of Childbearing Age}

The expert authors of this article undertook an exercise to rank the importance of a series of seven preselected issues (see Table 3) relating to the therapeutic use of DMDs in women of childbearing age. First, authors allotted a score of 1 (low impact) to 5 (high impact) as to their importance of these issues as potential drivers of a prescribing decision; the average score for each allowed ranking in terms of importance, as shown below, in descending order of importance.
The presence of a clinical indication for use during pregnancy was the highest-rated factor, following known low risk of teratogenicity, and a short washout period in case of a need to switch treatment in the event of a pregnancy. The existence of positive clinical data for treatment-exposed pregnancies was rated the next highest, and the relatively low ranking of this issue reflected the general lack of data available for most DMDs. Provision of a time window of controlled disease to permit the course of a pregnancy was rated the next highest. Finally, issues relating to lactation (therapeutic indication and existence of positive data) were the rated least important. 
TABLE 2: Summary of evidence relating to the foetal safety of DMDs used for relapsing-remitting multiple sclerosis.

\begin{tabular}{|c|c|}
\hline $\mathrm{DMD}$ & Overview of evidence relating to safety during pregnancy \\
\hline Alemtuzumab $^{\mathrm{a}}$ & $\begin{array}{l}\text { (i) No apparent increase in the frequency of spontaneous abortions between women who had received } \\
\text { alemtuzumab and women in the general population (2017, based on } 248 \text { pregnancies) [27]. }\end{array}$ \\
\hline Cladribine tablets $^{\mathrm{a}}$ & $\begin{array}{l}\text { (i) Similar proportions of live births and spontaneous abortion in women who received cladribine tablets or } \\
\text { placebo during the clinical development of this DMD (2017, based on } 64 \text { pregnancies) [28]. }\end{array}$ \\
\hline Dimethyl fumarate & $\begin{array}{l}\text { (i) No signal for adverse pregnancy outcomes in } 63 \text { women in clinical trials and } 125 \text { pregnancies described } \\
\text { postmarketing (2015) [29]. } \\
\text { (ii) International Registry data (194 pregnancies) showed unremarkable rates of pregnancy loss and birth defects } \\
\text { (2019) [30]. }\end{array}$ \\
\hline Fingolimod/siponimod ${ }^{\mathrm{a}}$ & $\begin{array}{l}\text { (i) Prospective Multinational Gilenya }{ }^{\circledR} \text { Pregnancy Exposure Registry found a rate of birth defects consistent with } \\
\text { the range found in the general population (based on 1,586 pregnancies, 2019) [31]. } \\
\text { (ii) A review by the EMA found a 2-fold increase in the rate of birth malformations (2019) [32]. }\end{array}$ \\
\hline Glatiramer acetate (GA) & $\begin{array}{l}\text { (i) Registry data suggest no teratogenic effect (based on } 246 \text { pregnancies, } 151 \text { with exposure in the } 1 \text { st trimester, } 3 \\
\text { to the 3rd trimester, } 95 \text { unexposed controls, 2016) [33]. } \\
\text { (ii) Comparison of a database including 5,042 pregnancies exposed to GA with control databases including } 29 \% \text { of } \\
\text { the European births ( }>1.7 \text { million/year) and }>50,000 \text { births in the USA showed no excess birth defects or other } \\
\text { adverse pregnancy outcomes (2018) [34]. }\end{array}$ \\
\hline
\end{tabular}

(i) 2,148 exposed and 2,025 unexposed pregnancies from the German Multiple Sclerosis and Pregnancy Registry Interferon beta $(\operatorname{INF} \beta)$ (2016), the Merck Serono Global Drug Safety Database (2011), and a Nordic Pregnancy Registry (2018) showed no excess risk to the foetus resulting from exposure o INF $\beta$ (live births, spontaneous abortions, congenital abnormalities, and birth length/weight) relative to the general population [35-37].

(i) Registry data included 101 women with RRMS foetal exposure to natalizumab, 78 women with RRMS and pregnancy unexposed to natalizumab, and 97 control; non-MS pregnancies demonstrated no significant differences for major malformations, low birth weight $(<2500 \mathrm{~g})$, or premature birth (2015) [38].

Natalizumab $^{\mathrm{a}} \quad$ (ii) Observational data suggested odds ratio of 3.9 for spontaneous abortion with natalizumab vs. INF $\beta$ or no treatment $(p<0.001)$; the frequency of spontaneous abortion $(17.4 \%)$ and of major congenital abnormalities (3.7\%) was within estimates for the local general population (92 exposed pregnancies 2018) [39].

(iii) No excess risk of miscarriages or birth defects global Tysabri Pregnancy Exposure Registry (376 pregnancies, 2016) [40].

Ocrelizumab $^{\mathrm{a}}$

(i) No signal for increased rates of spontaneous abortion in for 267 pregnancies (118 with documented foetal exposure). No foetal abnormalities were reported for 26 live births from these women (2019) [41].

(i) Spontaneous abortion rate of $18.6 \%$ from 70 pregnancies with known exposure to teriflunomide; this was described as within the expected range for the general population (2019) [42].

Teriflunomide

(ii) Spontaneous abortion rate of $21 \%$ from 431 exposed pregnancies, and 4 birth defects (these were considered consistent with the rate in the general population (2019) [43].

(iii) 587 pregnancies exposed to leflunomide (for arthritis) did not suggest teratogenic potential (7\% birth defects; 2019) [44].

Dates are years of publication or presentation at an international meeting. EMA: European Medicines Agency. RRMS: relapsing-remitting multiple sclerosis.

${ }^{a}$ Usually considered a high-efficacy disease-modifying drug (DMD) for the management of RRMS (see reference [19]).

TABLE 3: Authors' rating of issues relevant to the therapeutic use of a DMD in women of childbearing potential.

\begin{tabular}{lc}
\hline Issue & Average rating \\
\hline Existence of a therapeutic indication or use during pregnancy & 4.5 \\
Known low risk of teratogenicity & 4.3 \\
Short washout period if withdrawn & 4.1 \\
Positive data from DMD-exposed pregnancy & 3.7 \\
Provision of a sufficient period of controlled disease to complete a pregnancy & 3.5 \\
Existence of a therapeutic indication or use during lactation & 3.3 \\
Positive data from breastfeeding women taking the DMD & 2.9 \\
\hline
\end{tabular}

Experts allotted a score of 1 (low) to 5 (high) reflecting the importance of each issue as a driver of prescribing decisions for a woman of childbearing potential, and average scores for each issue are shown here. 
The impact of issues relating to potential pregnancy and lactation were considered separately for individual DMDs, according to the patient's level of MS disease activity. Consideration of possible future pregnancy would drive prescription of $\operatorname{INF} \beta$, and to a slightly lesser extent glatiramer acetate, more strongly than DMF or teriflunomide for a patient with mild-to-moderate disease activity. This was consistent with the greater availability of clinical data for INF $\beta$ and glatiramer acetate in this setting. Positive evidence for natalizumab in pregnancy, and its lack of a formal contraindication in pregnancy in Europe, drove higher ratings of this agent for women of childbearing potential who had high disease activity. The potential of IRT to provide a disease- and treatmentfree window of opportunity to pursue a pregnancy drove a high rating for cladribine tablets associated with this issue, although general restrictions on the use of alemtuzumab due to potential safety concerns were noted. Formal contraindications during pregnancy (and need to withdraw treatment should pregnancy occur), and long washout periods, impacted negatively on prescribing of ocrelizumab and fingolimod.

\section{Conclusions}

A diagnosis of RRMS has been perceived as a barrier to achieving a fulfilling family life for too long. Several studies based on registries, described above, show that a substantial minority of women undergo elective termination of unplanned pregnancies that have been exposed to DMDs taken for RRMS [27-44]. Perceptions of the barriers to having a family of women with MS appear to be reducing: data from the USA showed that the proportion of women with MS who are pregnant increased steadily between 2006 and 2014, in contrast to a decreasing proportion of women without MS who were pregnant over the same period [50]. This is a welcome development, which must be continued. It is important that physicians continue to reassure and support women with MS (and their partners) in feeling confident that they can raise a family, including providing support and reassurance for breastfeeding, where this is possible.

It remains important to prevent relapses as far as possible during pregnancy, and the increasing choice of DMDs has provided more flexibility here. Practical therapeutic options for treatment up to and including pregnancy are now available for women with active MS but lower disease activity who require active treatment. For example, INF $\beta$ now has a formal therapeutic indication for such patients, and in our experience, this development has helped to persuade patients of the benefits of maintaining treatment during pregnancy, who would otherwise be reluctant to continue treatment. GA represents a further possible option for these patients. Women with higher levels of disease activity requiring maintained treatment with a high-efficacy DMD could in principle be treated with natalizumab (to 30 weeks), or possibly with an IRT for women who are prepared to delay their pregnancy until the treatment course and associated washout period have been completed.

\section{Conflicts of Interest}

The authors declare that they have no conflicts of interest.

\section{Acknowledgments}

All authors participated in the closed meeting that gave rise to this article, which was organised and supported by Merck Serono Middle East FZ-Ltd, United Arab Emirates, an affiliate of Merck KGaA, Darmstadt, Germany. Nuha AlKhawajah reports personal fees and nonfinancial support from Merck for the submitted work, nonfinancial support from Genzyme, speaker honorarium from Novartis and Merck, research funding from Merck, and consultancy fees from Hikma, Merck, and Novartis outside the submitted work. Yasser Al Malik reports personal fees and nonfinancial support from Merck for the submitted work. Ibtisam AlThubaiti reports personal fees from Merck for the submitted work and personal fees from Novartis and Merck, outside the submitted work. Saeed Bohlega reports personal fees and nonfinancial support from Merck for the submitted work, grants from King Abdulaziz city for Science and technology and King Salman Center for Disability Research, personal fees from Biogen/Biologix, Sanofi, Novartis, Abbvie, and Merck, and nonfinancial support from Biogen/Biologix, Sanofi, Novartis, Merck, and Abbvie, outside the submitted work. Reem F. Bunyan reports personal fees from Merck for the submitted work, personal fees from Roche, personal fees from Novartis, and personal fees from Merck, outside the submitted work. Marinella Clerico reports personal fees and nonfinancial support from Merck for the submitted work, grants from Merck, Novartis, Biogen, Sanofi-Genzyme, and personal fees and nonfinancial support from Almirall, Novartis, Biogen, Sanofi-Genzyme, and Roche, outside the submitted work. Edward J Cupler reports personal fees and nonfinancial support from Merck for the submitted work, personal fees and nonfinancial support from Roche, personal fees and nonfinancial support from Sanofi, personal fees and nonfinancial support from Biogen/Biologix, personal fees from Novartis, personal fees and nonfinancial support from Merck, and grants from MENACTRIMS, outside the submitted work. Ahmed ElBoghdady is an employee of Merck KGaA, Riyadh, Saudi Arabia. Ahmed Hassan reports personal fees and nonfinancial support from Merck for the submitted work. Mohammed Al Jumah reports personal fees and nonfinancial support from Merck for the submitted work, grants from KACST, KAIMRC, Merck, personal fees from Merck, Biogen, Biologix, Bayer, Novartis, Roche, Sanofi, Genzyme, and Genpharm, and nonfinancial support from Merck, Biogen, Biologix, Bayer, Roche, and Sanofi, outside the submitted work. Yaser Al Malik reports personal fees and nonfinancial support from Merck for the submitted work, grants, personal fees, and nonfinancial support from Roche, personal fees from Novartis, personal fees from Biogen/Biologix, personal fees and nonfinancial support from Genzyme, and personal fees and nonfinancial support from Merck, outside the submitted work. Eman Nassim Ali reports personal fees and nonfinancial support from Merck for the submitted work, personal fees from Biogen/Biologix, and nonfinancial 
support from Novartis, Sanofi, and Merck, outside the submitted work. Jameelah Saeedi reports personal fees from Merck for the submitted work and personal fees and nonfinancial support from Roche, Novartis, Biogen/Biologix, and Merck, outside the submitted work. A medical writer (Dr Mike Gwilt, GT Communications) provided editorial assistance, funded by Merck Serono Middle East FZ LTD, an affiliate of Merck KGaA, Darmstadt, Germany.

\section{References}

[1] Multiple Sclerosis International Federation, Atlas of MS. Third edition. September 2020. Part 1. Mapping multiple sclerosis around the worldOctober 2020, https://www.atlasofms.org/ what-is-the-atlas-of-ms.

[2] M. AlJumah, R. Bunyan, H. al Otaibi et al., "Rising prevalence of multiple sclerosis in Saudi Arabia, a descriptive study," BMC Neurology, vol. 20, no. 1, p. 49, 2020.

[3] A. M. Langer-Gould, "Pregnancy and family planning in multiple sclerosis," CONTINUUM: Lifelong Learning in Neurology, vol. 25, no. 3, pp. 773-792, 2019.

[4] S. C. Smeltzer, "Reproductive decision making in women with multiple sclerosis," Journal of Neuroscience Nursing, vol. 34, no. 3, pp. 145-157, 2002.

[5] F. Ghafoori, N. Dehghan-Nayeri, Z. Khakbazan, M. Hedayatnejad, and S. M. Nabavi, "Pregnancy and motherhood concerns surrounding women with multiple sclerosis: a qualitative content analysis," International journal of community based nursing and midwifery, vol. 8, pp. 2-11, 2020.

[6] S. F. Wesley, M. Fabian, and S. Krieger, "Exploring patients' knowledge and misconceptions about multiple sclerosis and pregnancy," US Neurology, vol. 12, no. 1, pp. 34-38, 2016.

[7] C. Confavreux, M. Hutchinson, M. M. Hours, P. CortinovisTourniaire, and T. Moreau, "Rate of pregnancy-related relapse in multiple sclerosis. Pregnancy in Multiple Sclerosis Group," New England Journal of Medicine, vol. 339, pp. 285-291, 1998.

[8] K. Hellwig and R. Gold, "Family planning and multiple sclerosis," Aktuelle Neurologie, vol. 37, pp. 292-303, 2010.

[9] A. Langer-Gould, J. B. Smith, K. B. Albers et al., "Pregnancyrelated relapses and breastfeeding in a contemporary multiple sclerosis cohort," Neurology, vol. 94, no. 18, pp. e1939-e1949, 2020.

[10] A. M. Alanazi, J. R. al-Rashoud, J. M. Aljahani et al., "Exploring the outcome of multiple sclerosis among Saudi adult patients. A single-centered cross-sectional study at King Abdulaziz Medical City in Riyadh, Saudi Arabia," Neurosciences, vol. 24, no. 3, pp. 168-175, 2019.

[11] J. J. Cerqueira, D. A. S. Compston, R. Geraldes et al., “Time matters in multiple sclerosis: can early treatment and longterm follow-up ensure everyone benefits from the latest advances in multiple sclerosis?," Journal of Neurology, Neurosurgery \& Psychiatry, vol. 89, no. 8, pp. 844-850, 2018.

[12] R. Dobson, P. Dassan, M. Roberts, G. Giovannoni, C. NelsonPiercy, and P. A. Brex, "UK consensus on pregnancy in multiple sclerosis: 'Association of British Neurologists' guidelines," Practical Neurology, vol. 19, pp. 106-114, 2019.

[13] M. Al Sheeha, "Awareness and use of contraceptives among Saudi women attending primary care centers in Al-qassim, Saudi Arabia," International Journal of Health Sciences, vol. 4, pp. 11-21, 2010.
[14] F. Alhusain, F. Alkaabba, N. Alhassan et al., "Patterns and knowledge of contraceptive methods use among women living in Jeddah, Saudi Arabia," Saudi Journal for Health Sciences, vol. 7, no. 2, pp. 121-126, 2018.

[15] H. A. Al-Turki, "Contraception: attitudes and experiences of Saudi Arabian women," Health Care for Women International, vol. 32, no. 2, pp. 134-139, 2011.

[16] S. N. Khalil, M. M. Alzahrani, and A. F. Siddiqui, "Unmet need and demand for family planning among married women of Abha, Aseer Region in Saudi Arabia," Middle East Fertility Society Journal, vol. 23, no. 1, pp. 31-36, 2018.

[17] A. Abdulwahab, A. Almotairi, W. Alkhamis, and A. Almutiari, "Prevalence of unplanned pregnancy and its psychological effect among pregnant patients in King Khalid University Hospitals," The Egyptian Journal of Hospital Medicine, vol. 70, no. 6, pp. 943-947, 2018.

[18] R. Rochat, G. Farhat, and E. Almaghaslah, Do Saudi women have unplanned pregnancies? Abstract presented at the 2017 meeting of the American Public Health AssociationFebruary 2017, https://apha.confex.com/apha/2017/meetingapp.cgi/ Paper/384926.

[19] R. Alroughani, J. S. Inshasi, D. Deleu et al., "An overview of high-efficacy drugs for multiple sclerosis: Gulf region expert opinion," Neurology and Therapy, vol. 8, no. 1, pp. 13-23, 2019.

[20] B. Barry, A. A. Erwin, J. Stevens, and C. Tornatore, "Fingolimod rebound: a review of the clinical experience and management considerations," Neurology and Therapy, vol. 8, pp. 241250, 2019

[21] M. Sepúlveda, C. Montejo, S. Llufriu et al., "Rebound of multiple sclerosis activity after fingolimod withdrawal due to planning pregnancy: analysis of predisposing factors," Multiple Sclerosis and Related Disorders, vol. 38, article 101483, 2020.

[22] N. Behrangi, F. Fischbach, and M. Kipp, "Mechanism of siponimod: anti-inflammatory and neuroprotective mode of action," Cells, vol. 8, p. E24, 2019.

[23] A. Haghikia, A. Langer-Gould, G. Rellensmann et al., "Natalizumab use during the third trimester of pregnancy," JAMA Neurology, vol. 71, no. 7, pp. 891-895, 2014.

[24] P. S. Sorensen and F. Sellebjerg, "Pulsed immune reconstitution therapy in multiple sclerosis," Therapeutic Advances in Neurological Disorders, vol. 12, article 1756286419836913, 2019.

[25] M. AlJumah, M. M. Alkhawajah, S. Qureshi et al., "Cladribine tablets and relapsing-remitting multiple sclerosis: a pragmatic, narrative review of what physicians need to know," Neurology and Therapy, vol. 9, no. 1, pp. 11-23, 2020.

[26] I. A. AlSharoqi, M. Aljumah, S. Bohlega et al., "Immune reconstitution therapy or continuous immunosuppression for the management of active relapsing-remitting multiple sclerosis patients? a narrative review," Neurology and Therapy, vol. 9, no. 1, pp. 55-66, 2020.

[27] D. Rog, O. Jiwon, and C. Chambers, "Pregnancy outcomes in patients with RRMS treated with alemtuzumab from the clinical development program. Abstract (P749) and poster at the ECTRIMS 2017 congress," October 2020, https://onlinelibrary .ectrims-congress.eu/ectrims/2017/ACTRIMS-ECTRIMS2017/ 200404/david.rog.pregnancy.outcomes.in.patients.with.rrms .treated.with.alemtuzumab.html.

[28] A. Galazka, A. Nolting, S. Cook et al., "Pregnancy outcomes during the clinical development programme of cladribine in 
multiple sclerosis (MS): an integrated analysis of safety for all exposed patients. Abstract (P1874) at the ECTRIMS 2017 congress," October 2020, https://onlinelibrary.ectrims-congress .eu/ectrims/2017/ACTRIMS-ECTRIMS2017/199894/vicky .john.pregnancy.outcomes.during.the.clinical.development .programme.of.html.

[29] R. Gold, J. T. Phillips, E. Havrdova et al., "Delayed-release dimethyl fumarate and pregnancy: preclinical studies and pregnancy outcomes from clinical trials and postmarketing experience," Neurology and Therapy, vol. 4, no. 2, pp. 93104,2015

[30] K. Hellwig, D. Rog, C. McGuigan, K. Chen, B. Parks, and C. C. Jones, "An international registry tracking pregnancy outcomes in women treated with dimethyl fumarate. Abstract (P1147) at the ECTRIMS 2019 congress," October 2020, https:// onlinelibrary.ectrims-congress.eu/ectrims/2019/stockholm/ 278349/kerstin.hellwig.an.international.registry.tracking .pregnancy.outcomes.in.women.html.

[31] S. Lopez Leon, Y. Geissbuehler, and A. Moore, "Effect of fingolimod on pregnancy outcomes in patients with multiple sclerosis. Abstract (P411) at the ECTRIMS 2019 congress," October 2020, https://onlinelibrary.ectrims-congress.eu/ectrims/2019/ stockholm/278772/kerstin.hellwig.effect.of.fingolimod.on .pregnancy.outcomes.in.patients.with.html.

[32] European Medicines Agency, "Updated restrictions for Gilenya: multiple sclerosis medicine not to be used in pregnancy," October 2020, Press release 26/07/2019, https://www.ema .europa.eu/en/news/updated-restrictions-gilenya-multiplesclerosis-medicine-not-be-used-pregnancy.

[33] S. Herbstritt, A. Langer-Gould, M. Rockhoff et al., "Glatiramer acetate during early pregnancy: a prospective cohort study," Multiple Sclerosis Journal, vol. 22, no. 6, pp. 810-816, 2016.

[34] M. Sandberg-Wollheim, O. Neudorfer, A. Grinspan et al., "Pregnancy outcomes from the branded glatiramer acetate pregnancy database," International Journal of MS Care, vol. 20, no. 1, pp. 9-14, 2018.

[35] S. Thiel, A. Langer-Gould, M. Rockhoff et al., "Interferon-beta exposure during first trimester is safe in women with multiple sclerosis-a prospective cohort study from the German Multiple Sclerosis and Pregnancy Registry," Multiple Sclerosis Journal, vol. 22, no. 6, pp. 801-809, 2016.

[36] M. Sandberg-Wollheim, E. Alteri, M. S. Moraga, and G. Kornmann, "Pregnancy outcomes in multiple sclerosis following subcutaneous interferon beta-1a therapy," Multiple Sclerosis Journal, vol. 17, no. 4, pp. 423-430, 2011.

[37] K. Hellwig, Y. Geissbuehler, M. Sabidó et al., "Pregnancy and infant outcomes with interferon beta: data from the European Interferon Beta Pregnancy Registry and Population Based Registries in Finland and Sweden. Abstract (A-0950-0000-02658) and poster at the ECTRIMS 2018 congress," October 2020, https://onlinelibrary.ectrims-congress.eu/ectrims/2018/ ectrims-2018/228131/kerstin.hellwig.pregnancy.and.infant .outcomes.with.interferon.beta.data.from.html.

[38] N. Ebrahimi, S. Herbstritt, R. Gold, L. Amezcua, G. Koren, and K. Hellwig, "Pregnancy and fetal outcomes following natalizumab exposure in pregnancy. A prospective, controlled observational study," Multiple Sclerosis Journal, vol. 21, no. 2, pp. 198-205, 2015.

[39] E. Portaccio, P. Annovazzi, A. Ghezzi et al., "Pregnancy decision-making in women with multiple sclerosis treated with natalizumab: I: Fetal risks," Neurology, vol. 90, no. 10, pp. e823e831, 2018.
[40] S. Friend, S. Richman, G. Bloomgren, L. M. Cristiano, and M. Wenten, "Evaluation of pregnancy outcomes from the Tysabri ${ }^{\circledR}$ (natalizumab) pregnancy exposure registry: a global, observational, follow-up study," BMC Neurology, vol. 16, no. 1, p. 150, 2016.

[41] C. Oreja-Guevara, S. Wray, R. Buffels, D. Zecevik, and S. Vukusik, "Pregnancy outcomes in patients treated with ocrelizumab. Abstract (P780) and poster at the ECTRIMS 2019 congress," October 2020, https://onlinelibrary.ectrimscongress.eu/ectrims/2019/stockholm/279140/celia.orejaguevara.pregnancy.outcomes.in.patients.treated.with .ocrelizumab.html.

[42] B. C. Kieseier and M. Benamor, "Pregnancy outcomes following maternal and paternal exposure to teriflunomide during treatment for relapsing-remitting multiple sclerosis," Neurology and Therapy, vol. 3, no. 2, pp. 133-138, 2014.

[43] S. Vukusic, P. K. Coyle, S. Jurgensen et al., "Pregnancy outcomes in patients with multiple sclerosis treated with teriflunomide: clinical study data and 5 years of post-marketing experience," Multiple Sclerosis Journal, vol. 26, no. 7, pp. 829-836, 2020

[44] L. J. Henson, S. Afsar, L. Davenport, A. Purvis, E. M. Poole, and P. Truffinet, "Pregnancy outcomes in patients treated with leflunomide, the parent compound of the multiple sclerosis drug teriflunomide," Reproductive Toxicology, vol. 95, pp. 45-50, 2020.

[45] S. Vukusic, K. Hellwig, P. Truffinet et al., "Pregnancy outcomes in female partners of male patients treated with teriflunomide or leflunomide (an in vivo precursor of teriflunomide). Abstract (P1146) at the ECTRIMS 2019 congress," October 2020, https://onlinelibrary.ectrims-congress.eu/ectrims/2019/ stockholm/278348/sandra.vukusic.pregnancy.outcomes.in .female.partners.of.male.patients.treated.html.

[46] T. W. Hale, A. A. Siddiqui, and T. E. Baker, "Transfer of interferon $\beta$-1a into human breastmilk," Breastfeeding Medicine, vol. 7, no. 2, pp. 123-125, 2012.

[47] C. Polman, F. Barkhof, L. Kappos et al., "Oral interferon beta1a in relapsing-remitting multiple sclerosis: a double-blind randomized study," Multiple Sclerosis Journal, vol. 9, no. 4, pp. 342-348, 2003.

[48] U. Proschmann, K. Thomas, S. Thiel, K. Hellwig, and T. Ziemssen, "Natalizumab during pregnancy and lactation," Multiple Sclerosis Journal, vol. 24, pp. 1627-1634, 2018.

[49] T. E. Baker, S. D. Cooper, L. Kessler, and T. W. Hale, “Transfer of natalizumab into breast milk in a mother with multiple sclerosis," Journal of Human Lactation, vol. 31, pp. 233-236, 2015.

[50] M. K. Houtchens, N. C. Edwards, G. Schneider, K. Stern, and A. L. Phillips, "Pregnancy rates and outcomes in women with and without MS in the United States," Neurology, vol. 91, no. 17, pp. e1559-e1569, 2018. 